\title{
CORRIGENDUM
}

\section{Repression of microRNA-768-3p by MEK/ERK signalling contributes to enhanced mRNA translation in human melanoma}

CC Jiang, A Croft, H-Y Tseng, ST Guo, L Jin, P Hersey and XD Zhang

Oncogene (2016) 35, 6044; doi:10.1038/onc.2016.144; published online 27 June 2016

Correction to: Oncogene (2013) 33, 2577-2588; doi:10.1038/onc. 2013.237; published online 17 June 2013

Since the publication of this article, the authors realised that Figures $4 \mathrm{a}$ and $6 \mathrm{~g}$ of our paper contained inadvertently

a

Full gel

Processed figure
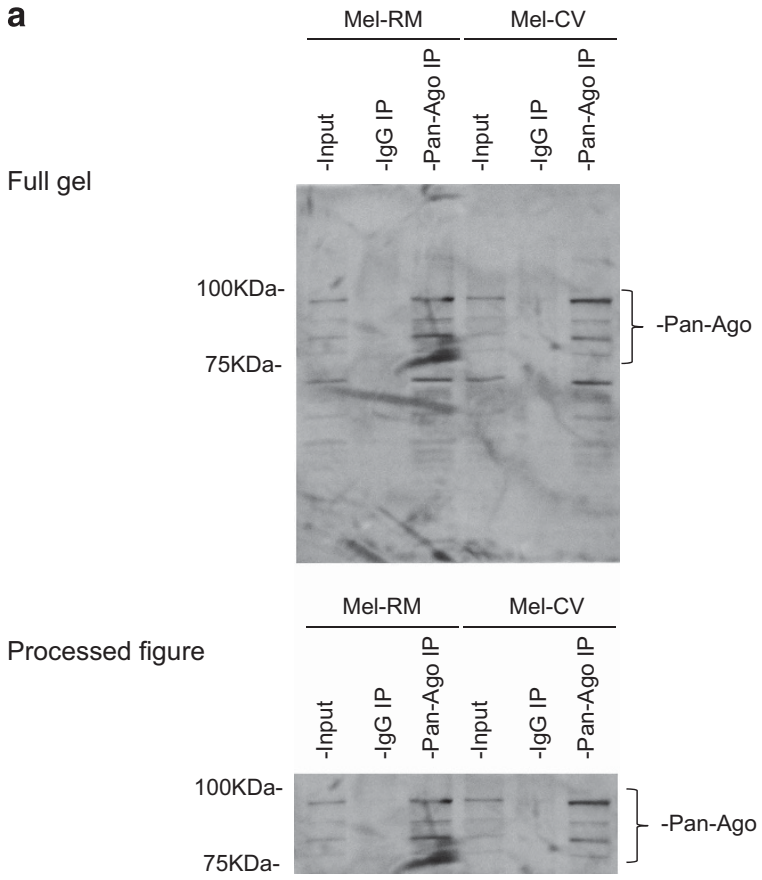

Figure 4. (a) Upper panel: Detection of Ago proteins in immunoprecipitates with an anti Ago (pan) antibody. Whole cell lysates were subjected to immunoprecipitation with a mouse anti Ago (pan) antibody or purified mouse lgG (as a control). The resulting precipitates were subjected to western blot analysis of Ago proteins. The data shown are representative of three individual experiments. duplicated images. Please see corrected images and figure legends below.

The authors apologise for any inconvenience caused by this error.

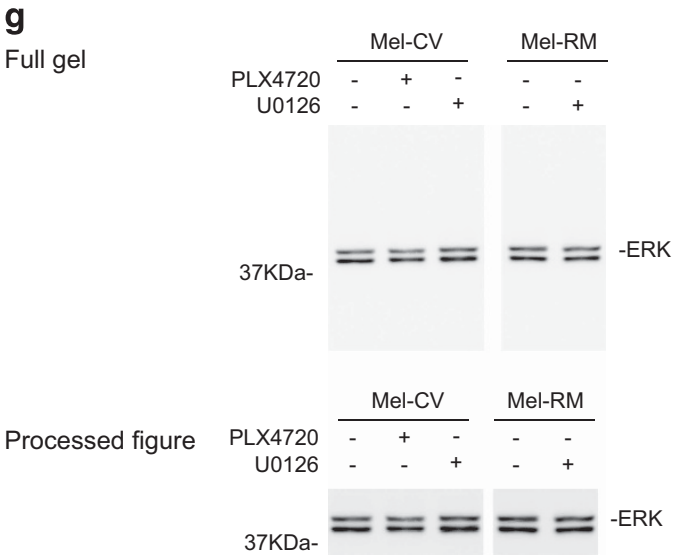

Figure 6. (g) Western blot analysis of ERK expression. Whole cell lysates from Mel-CV cells with or without treatment with PLX4720 $(5 \mathrm{~mm})$ or U0126 $(20 \mathrm{~mm})$ for $24 \mathrm{~h}$ and Mel-RM cells with or without treatment with $\mathrm{U} 0126(20 \mathrm{~mm})$ for $24 \mathrm{~h}$ were subjected to western blot analysis of ERK. The data shown are representative of three individual experiments. 